\title{
Post-truth: an outline review of the issues and what is being done to combat it
}

Posverdad: una revision esquemática de los problemas y de qué se está haciendo para combatirla

\author{
Alan GILCHRIST \\ Reino Unido, alangilchrist77@gmail.com
}

\begin{abstract}
Resumen
Se discute el nuevo y perturbador fenómeno de la posverdad atendiendo especialmente al papel jugado por los 'gigantes tecnológicos', los motores de búsqueda y los medios sociales. El uso de estas infraestructuras de comunicación se examina en relación con su manipulación y explotación para difundir noticias falsas and desinformación. Se discute la lucha contra la posverdad, liderada por periodistas, académicos y profesionales de la información, cuyo papel se analiza con especial detalle. También se menciona el rol de gobierno y de las grandes empresas. El combate contra la posverdad se desarrolla en tres frentes principales: elevar la alerta social, promover la alfabetización informacional y favorecer la verificación de hechos. Se analizan los avances realizados en sitios de comprobación factual y en los procesos de verificación automatizada de evidencias.
\end{abstract}

Palabras clave: Noticias falsas. Desinformación. Medios sociales. Verificación de hechos. Verificación de hechos automática. Alfabetización información. Regulación gubernamental. Grandes empresas tecnológicas. Periodistas. Académicos. Profesionales de la información.

When words lose their meaning, people lose their freedom. (Confucius, 551-479 BCE)

\section{Introduction and Rationale}

The Oxford Dictionaries in 2016 named "PostTruth" as the "International Word of the Year". While the underlying concept of the term is not entirely new, its modern manifestations have recently become remarkably common in many countries of the world and show no signs of abating. Snyder, Professor of History at Yale University, in his book On Tyrrany: Twenty Lessons from the 20th Century, (Snyder, 2017) includes a chapter with the title "Believe in Truth" which ends with the words "Post-Truth is pre-fascism", and while this statement may be too pessimistic there is little doubt that the phenomenon is extremely dangerous and must be widely viewed as such and combated accordingly by all who care for rationality and democracy. It is a belief put forward

\begin{abstract}
The new and disturbing phenomenon of "Post-Truth" is discussed with particular attention given to the power of the 'big-tech- giants' and the role of search engines and social media. The use made of these facilities is reviewed with particular regard to their manipulation and exploitation to spread fake news and disinformation. The fight against post-truth is discussed, led by journalists, academia and, with particular emphasis, by the information professions. The role of government and the big-tech companies is also mentioned. The fight includes raising awareness, promotion of information literacy and fact checking. Web-based fact checking sites and advances in automated fact checking are reviewed.
\end{abstract}

Keywords: Post-Truth. Fake news. Disinformation. Social media. Fact checking. Automated fact checking. Information literacy. Government regulations. Reactions by big tech. Journalists. Academia. Information professions.

in this paper that while the word 'all' in the previous sentence must include particularly those who have the most influence in the public sphere for their potential power to combat post-truth; that is the politicians, journalists, and teachers, it must also be true that those working in the information professions have important roles to play.

Information science is traditionally both an academic study of the theory and practice of information creation, processing, storage and transfer of information, and the practice of enabling and assisting its transfer between creator and recipient, a practice which was particularly active in the era of computer-assisted retrieval before the impact of automated searching on the World Wide Web and the subsequent disintermediation between information scientist and searcher. In both these activities information science was preceded by librarianship and library science, records management and archives management. The practitioners in these disciplines are now coming 
together, even if not officially, as 'Information Professionals' or 'Information Managers'. It can be argued that, in acting as intermediaries in the information communication chain, the information manager as used above has much in common with journalists and with teachers in that all are engaged in the discovery of information at its source(s) and, with varying aspects of transformation, processing it for consumption by the user(s). The term 'user' is employed here to include the recipient of both written and oral communication through both traditional channels and the wide-spread use of the Internet and particularly social media. It therefore follows that all three broad practices could, individually and together, make a strong and concerted effort to counter the alarming spread of what has come to be known as the "Post-truth Society". This paper examines the phenomenon of post-truth and what can be (and is being) done to combat it.

\section{Roots of the Post-Truth society}

The developments that have led to the post-truth society are many and complex, but three factors seem to be outstanding: Globalization, Populism and the Internet. The first two of these are not only outside the scope of this paper, but of the ability of the author to do more than report on a few writings by authors better qualified to comment; the third is more firmly within the scope of information science.

\subsection{Globalization, Populism (and Post- Modernism)}

The Oxford Dictionaries define Globalization as "The process by which businesses or other organizations develop international influence or start operating on an international scale." Initially seen by many as a force for good, there have been a number of effects which have given rise to major concern: the power of big corporations to override national requirements, for example by avoiding taxation and local regulations, and the associated increase in the wealth gap between rich and poor. These factors are further discussed by an author on the Forbes website (Collins, 2015)). It is argued by many that this global disruption has also led to alienation and unrest at the national and community levels of many countries, leading to nationalism, separatism and a lack of trust in the 'elite'. This last has become known as 'Populism'. The definition given in Wikipedia is, unusually, rather unbalanced giving "Populism is a political philosophy supporting the rights and power of the people in their struggle against a privileged elite". While this has some historical weight, the Oxford Dictionaries offer "A political approach that strives to appeal to ordinary people who feel that their concerns are disregarded by established elite groups" and a more nuanced account is given by The Economist weekly magazine on its website (M.S. 2016), which points out that the term was first used in America when the "Populist Movement" pitted rural populations and the Democratic Party against the more urban Republicans; and the term's use, while being somewhat fuzzy has since grown in use. The third of these complex and, in the context of post-truth, related concepts is the philosophical term postmodernism. The Oxford Dictionaries offer the definition

A late 20th century style and concept in the arts, architecture and criticism, which represents a departure from modernism and is characterized by the self-conscious use of earlier styles and conventions, a mixing of different artistic styles and media, and general distrust of theories.

It has been argued that in the context of posttruth, post-modernism has come to imply that anyone's opinions and beliefs are as valid as anybody else's.

\subsubsection{The Internet and the 'Tech Giants'}

While the three concepts described briefly in the previous section are clearly related to the posttruth phenomenon the fourth major influence, central to this paper and a key component of globalization is technology, the Internet and, in particular, social media. These channels are dominated by the four giants GAFA - Google, Apple, Facebook and Amazon, though others are beginning to grow. (A new acronym has emerged FANG, standing for Facebook, Amazon, Netflix and Google). A large component of the Internet is, of course, the World Wide Web, first made available to the public in 1991. Since then, according to a Web Server Survey (Fowler, 2018) there are now over 1.8 billion websites. Whatever the true number, it is certainly the case that the number passed one billion several years ago. Though there are many search engines available, the field is dominated by the U.S. organization Google. (It may be noted here that the second largest search engine in the world is China's Baidu with over three-quarters of the market in China, and which has very recently been bought by a giant Chinese e-commerce firm called Alibaba). Google is the largest Internet company by revenue and, according to Wikipedia that of Facebook was $\$ 40,653$ billion in 2017. These huge figures include vast incomes from advertising which is having a severe adverse effect on the financial health of print on paper newspapers. The money involved in the operations of these 'tech giants' disturbs the Argentinian/Canadian author and bibliophile Alberto Manguel who has said: 
In our time, in order to create and maintain the huge and efficient machinery of financial profit, we have collectively chosen speed over deliberate slowness, intuitive responses over detailed critical reflection, the satisfaction of reaching snap conclusions rather than the pleasure of concentrating on the tension between various possibilities without demanding a conclusive end. If profit is the goal, creativity must suffer.

Many people, including governments, are becoming increasingly concerned at the power of these corporations and their monopolistic behaviour. What is as astonishing as the World Wide Web is the rapid rise in social media sites, dominated by another U.S. conglomerate Facebook. According to Wordstream (Lister, 2018), Facebook has 2,047 million users. Furthermore, Facebook owns WhatsApp in third place, with 1,200 million users, Facebook Messenger in fourth place with 1.200 million and Instagram in seventh place with 700 million. The second overall place is held by YouTube owned by Google with 1,500 million users. Again, China is rising fast with three sites in the first ten by numbers of users; these are WeChat, QQ and Qzone, all owned by Tencent. The others in the global first ten, Tumblr and Twitter, are also American. All of this amounts to a colossal amount of 'information' available through the Web and the social media sites (of which only the biggest are mentioned above). In his excellent short book Post Truth, D'Ancona (D'Ancona, 2017), discussing post-modernism, quotes Baudrillard, one of the notorious school of French post-modern philosophers, in a prescient comment made in the early 1990s:

We live in a world where there is more and more information, and less and less meaning...Despite efforts to re-inject message and content, meaning is lost and devoured faster than it can be re-injected. Everywhere socialization is measured by the exposure to media messages. Whoever is underexposed to the media is de-socialized or virtually asocial [...] where we think that information produces meaning, the opposite occurs.

\section{Definitions}

\subsection{Fundamentals}

We live in a turbulent world in which many words are changing their meanings, or at least becoming less exact. Two such words are 'information' and 'knowledge', especially when used in such phrases as the 'information society' or the 'knowledge economy'. In order to fully understand the significance of the new term 'post-truth' it is necessary to reiterate here the analyses of the words information and knowledge as described by eminent information scientists. Ingwersen (Ingwersen, 1996), in one of the most thorough analyses (and for the purposes of this paper the most helpful) brings together the concepts of knowledge, information, cognition and perception in a diagram from which it can be seen that the whole and necessarily personal process of acquisition involves the alteration of an individual's 'knowledge state' into a new and current 'cognitive state' which is subject to the effects of both cognitive and emotional influences; an important point which will be discussed in more detail later in this paper. Nonaka and Takeuchi (Nonaka and Takeuchi, 1995) stress the difference between what they call 'explicit knowledge' that is "easily codified and conveyed" and 'tacit knowledge' which they describe as "experimental know-how", and which is transmitted orally. Floridi (Floridi, 2010) brings together the two terms information and knowledge, adding the term data in a 'map of information concepts' that follows the path from Data (structured) to either Instructional or Semantic (content) being 'factual' but, importantly, either untrue or true. The latter leads to knowledge and the former to either 'misinformation' (unintentional) or 'disinformation' (intentional), a distinction which is important in the discussion of post-truth. In an attempt to avoid the ambiguities of the terms information and knowledge, Belkin and Robertson (Belkin and Robertson, 1976) proposed the use of the neutral term 'Message(s)' which can refer to either its physical manifestation or its abstract content; a term with useful resonance in the age of social media. Finally, Bawden and Robinson introduce the word 'understanding' in a paper under the title "Information and the gaining of understanding" (Bawden and Robinson, 2016). They suggest that "In addition to data, information and knowledge, the information sciences should focus on understanding, understood as a higher order knowledge, with coherent and explanatory potential". Though the authors do not put forward this suggestion in the context of the post-truth phenomenon, it will be seen later in this paper that it is, indeed, relevant.

\subsubsection{Post-Truth and Fake News}

The previous paragraph sought to show that the words 'information' and 'knowledge' need to be addressed with caution as both can be understood only in the context of an individual's unique perception. Shared knowledge or consensus carries more weight but, as will be shown below, does not necessarily amount to truth. Plato is often credited with the statement "Truth is justified belief", but this was refuted by, amongst others, the English philosopher Bertrand Russell, who suggested that someone checking the time and seeing that the clock read two p.m. would be justified in believing the reading, ignorant of the fact that although it was in fact two p.m. the clock had stopped 12 hours previously. The term 'Post- 
truth' must therefore be viewed as an adjective for situations in which mis- and disinformation are present, and it therefore follows that there are several manifestations in which this situation arises. The Oxford Dictionaries, mentioned above, define Post-truth as "An adjective relating to circumstances in which objective facts are less influential in shaping public opinion than emotional appeals". This word 'Truth' has been a subject for centuries and debated by many philosophers, so it is not surprising to see some of today's philosophers considering the phenomenon of post-truth. Grayling (Coughlan, 2017) takes a pessimistic view, warning of the "corruption of intellectual integrity" and damage to "the whole fabric of democracy", while Baggini (Baggini, 2017) views the phenomenon, albeit as wide-spread and serious, as one that occurs in cycles and now giving us the opportunity to take a deeper look at the meaning and importance of the concept of truth.

One of the more visible manifestations of posttruth is fake news. A number of authors have described this with varying degrees of detail. One of the simplest is put forward by Verstraete et al. of the University of Arizona (Verstraete, Bambauer and Bambauer, n.d.) in the form of a 2x2 matrix, in which the vertical entries are headed 'Deceive' and 'Not deceive' and the horizontal entries 'Financial' and 'Not financial' leading to the four types Hoax, Propaganda, Satire and Humor, but the authors point out that these may be combined in a single piece of fake news. This point is stressed by Wardle in her contribution headed "Fake News. It's Complicated" (Wardle, 2017). Wardle works with the American Shorenstein Center on Media, Politics and Public Policy and presents a table of seven types of fake news which she describes as "an ecosystem of misinformation". Her seven types are Satire or Parody, Misleading content, Imposter content, Fabricated content, False connection, False context, and Manipulated content. These are then plotted in a 'Misinformation matrix' against their qualities or intentions: Poor journalism, To parody, To provoke, Passion, Partisanship, Profit, Political influence, Propaganda. Finally, an author at EAVI (the Embodied AudioVisual Interaction group) (Steinberg, 2017), a non-profit organisation based in Brussels and partnered by, amongst others UNESCO, and other smaller branches of the United Nations and of the European Union, have gone even further by putting forward ten types of fake news. These are: Propaganda, Clickbait (enticement to go further), Sponsored content, Satire and Hoax, Error, Partisan, Conspiracy theory, Pseudo-science, Misinformation, Bogus. These three contributions confirm that fake news is certainly complicated and that more work needs to be done to establish a more rigorous classification, but for the time being they provide some useful guidance. Finally, one of the more bizarre neologisms in this section which occurred just after the election of Donald Trump. The new President, irritated by the report that his predecessor's inauguration had been attended by a far greater number than his, asked his Press Secretary to deny it, which he did. This denial was strongly rebutted by others supported with visual evidence, but the next day a senior aide to the President defended the Press Secretary by claiming he was merely presenting "alternative facts".

\section{Use and Abuse}

\subsection{Users}

Considering the enormous range and amount of information available through the various search engines, and adding the new paradigm of the 'information chain' of social media used by millions of people as authors (and 'publishers'), 'readers' and even intermediaries in the sense that they can pass on messages with one click recording 'like', 'dislike' or 'share', we have a radically different situation, with an extremely wide divergence from the classical information chain consisting of Author - Publisher - (Professionally trained) Intermediary - Reader. This changes the entire nature of the process from one which was reasonably highly controlled to one which can almost be described as anarchic, and where motives for communicating, and reactions to receiving communications, are subject to very many factors. The definition of Post-Truth offered at the beginning of this paper suggested that the primary factor was that emotions played a greater influence on reading 'messages' than on rationality. This aspect is perhaps more important in considering how people are exploited on social media and this will be discussed below, but other fundamental factors also come into play. Ball (Ball, 2017) discusses three that can distort independent thinking in the use of social media. The first is that people tend to agree with what supports their current beliefs, a phenomenon known as 'confirmation bias'. This can be so strong that, as some studies have shown, these beliefs can actually be reinforced by people when challenged with strong counter-arguments - a reaction known as the 'backfire effect'. Ball goes on to suggest that a major problem in many discussions is the common relative inability to understand statistics (A wellknown example is the comparison of plane and car accidents where one source says that "Flying is actually the safest mode of transportation. In fact, the odds of a plane crash are one for every 1.2 million flights with odds of dying one in $11 \mathrm{mi}-$ llion. Your chances of dying in a traffic accident 
are one in 5,000"). A significant result of confirmation bias is that 'group identity' becomes powerful, leading to polarisation and the existence of echo chambers; "in which beliefs are amplified or reinforced by communication and repetition inside a closed system". This common feature of social media led George Brown, one-time Prime Minister of the U.K., to say in his autobiography, and speaking as one who had been a politician for forty years before the World Wide Web and baffled by the pervasiveness of Twitter and other social media platforms in politics: "The Internet often functions like a shouting match without an umpire. Trying to persuade people through social media seems to matter less than finding an echo chamber that reinforces one's own point of view".

Horrigan (Horrigan, 2017) reporting on a Pew Research Center survey explains the creation of an 'information-engagement typology' constructed to research how people in the U.S. approach facts and information. The typology contains five groups under the three main headings of 'Relatively engaged with information', 'More ambivalent about information' and 'Relatively wary about information'. The survey showed that within the first group $22 \%$ of the total were found to be 'The eager and willing' and $16 \%$ 'The Confident'; the second main group contained just one sub-group of the 'Cautious and curious' totalling $13 \%$; while the third main group contained two sub-groups, 'The Doubtful' at $24 \%$ and 'The Wary' at $25 \%$. Amongst the findings of the survey Horrigan points out that "almost half the respondents are relatively disengaged and not very enthusiastic about information". In addressing this particular issue and concerned about how such attitudes might be changed, Horrigan suggests "How useful it would be if there were trusted institutions helping people gain confidence in their digitaland information-literacy skills" and adds "Libraries might be relevant here". In another survey, conducted by Nielsen and Graves from the Reuters Institute and the University of Oxford (Nielsen and Graves, n.d.), attitudes towards 'fake news' were studied. Among the six main findings were that "People saw the difference between fake news and news as one of degree", and gave examples of fake news as "Poor journalism, Propaganda (including both lying politicians and hyperpartisan content), and some kinds of Advertising", and lastly that "The fake news discussion plays out against a background of low trust in news media, politicians and platforms alike $-a$ generalized scepticism toward most of the actors that dominate the contemporary information environment". Trust is an important factor in understanding the post-truth phenomenon, and its implications will be further explored later in the paper, but it is appropriate to pick up here on
Horrigan's suggestion that libraries could be important. This is highlighted by the results of a recent poll commissioned by the U.K Chartered Institute of Librarians and Information Professionals (CILIP) and carried out on their behalf by a professional survey organisation (CILIP, 2018). This found that the most trusted group as judged by $74 \%$ of respondents were Medical workers, followed by Teachers and Police Officers, both on $49 \%$ - and these were followed by Librarians on $46 \%$. Lawyers on $39 \%$ fared reasonably well and better than Economists on $20 \%$ but the worrying result for Journalists was $6 \%$, three percentage points higher than Estate Agents - and even more worrying at the bottom of the list - Politicians on just $2 \%$. A survey conducted in the U.S by the Pew Research Center (Geiger, 2017) backs up part of the above findings when it declares that most Americans $(78 \%$, and mainly millennials) say "libraries can help them find reliable trustworthy information". The claim that post-truth involves emotions more than reason is well founded, but is also complex involving many and different aspects of emotion which is further influenced by the often-fleeting glance at a piece of information; thus, the eye is caught by the dramatic (as in conspiracy theories which abound on social media) or by sensational statements or headlines.

\subsection{Manipulation}

Donald Trump and Brexit have provided many examples of manipulation, many of which have been knowingly used by people in high places primarily addressing the populist sector. In the runup to the Brexit referendum in the U.K., Boris Johnson (promoted to the role of Foreign Secretary following the vote) stated that the U.K would, by "taking back control", gain roughly $£ 350,000$ million a week which would become available to spend on the National Health Service. This uncorroborated but catchy statement was even printed on the side of the 'battlebus' used in touring the country campaigning the benefits of leaving the European Union. This claim was rebutted by several reliable sources in great (and therefore, to many, unattractive detail). Despite this, Johnson repeated the claim following the vote, and was again rebutted by political and financial experts. Another prominent Government Minister, and leader of the pro-Brexit camp was rather more subtle in his use of the post-truth comment as reported by Botsman (Botsman, 2017), in her book titled Who can You Trust?, in which she recounts how Michael Gove pronounced in a TV interview before the referendum "I think people in this country have had enough of experts", which she regarded as a disturbing comment, that could be 
interpreted by many as an invitation to believe what you want to believe. The pro-Brexit press is also active in the use of catchy and memorable front-page headlines that tend to last longer in the mind than any rebuttals. One example of this from the U.K. paper the Daily Mail appearing in February 2018 was "Secret billionaire in plot to sabotage Brexit". (Note the evocative first, fourth and sixth words). The next day the well-known billionaire George Soros said it was no secret and that, not only was he financing a widely-known movement campaigning against Brexit, but that he was now doubling his donation in protest.

\subsection{Exploitation}

Exploitation is used here as a stronger word than manipulation, though the difference is largely a matter of degree and intent, as well as the medium used. While the examples in the previous section, knowingly perpetrated and disseminated through the traditional channels of newspapers and radio/television, were relatively trivial, there are far more serious examples. A recent case, reported in the U.K. press at the time of writing, shows dramatically how people can be fooled on the Internet, in this case by not checking the validity of websites. "A group set up 'copy-cat websites' that impersonated official government services to sell passports, driving licences and other key documents.... and... defrauded thousands of consumers out of more than $£ 37$ million". People tend to believe what they want to believe, as is shown by the investigative journalist Cadwalladr (Cadwalladr, 2017) in a newspaper report on an experience of a search on Google which started with the letters she keyed in: "a-r-e-" and then "je-w-s", at which stage Google kicked in with suggested full queries starting with "Are Jews a race?, "Are Jews white?", "Are Jews Christians" and in fourth place "Are Jews evil?". Selecting the last, Cadwalladr was horrified to find websites compiled by anti-Semitic, neo-Nazi groups full of hateful anecdotes. There is growing pressure on Google and other companies to look hard at this abuse of the search service and the algorithms that support it.

\section{The fight against Post-Truth}

\subsection{Awareness}

In the report cited earlier by Verstraete et al. (Verstraete, Bambauer and Bambauer, n.d.), the authors state quite rightly that "It is futile to place a significant share of the burden to solve fake news on readers". This section reviews some of the actions being undertaken by governments and international agencies, by academia and the various institutions of information professionals, by journalists and, slowly but increasingly, by the principal players, the "big tech" corporations themselves. The first step in drawing the public's attention to the problem of fake news is to define it, and then how to identify it. This was covered in the section on Definitions near the beginning of this paper, but it is worth mentioning an early post by the International Federation of Library Associations (IFLA) that is available on their website in 39 languages (IFLA, 2017). IFLA felt spurred into action when Oxford Dictionaries announced 'PostTruth' as the Word of the Year in 2016, leading them to say, "We as librarians realize action is needed to educate and advocate for critical thinking - a crucial skill when navigating the information society." They then put forward a set of eight pointers, which may have been taken from a list produced by Kiely and Robertson quoted later in this paper. Huwe, a librarian at one of the Institutes attached to the University of California echoes the potential importance of the contribution that the library sector should make in a short article under the strong title "Fake news and the librarian's duty of care " (Huwe, 2017). Huwe states "As information professionals our core values challenge us to cross organizational and ideological boundaries in search of trustworthy knowledge resources...it is one for which we are prepared. Our new remit is to offer targeted fact checking across all media - and to make sure our voices are heard". Much of the traditional print on paper news media were also quick to report on the new phenomenon, with the added incentive of hoping to claw back some of the advertising revenue that social media had taken away from them. The increased awareness of the problem resulting from these various actions seems to have had some effect, according to a survey carried out by the Edelman Trust, published in early 2018 (Edelman Trust, 2018). The survey carried out with 33,000 respondents in 28 countries showed that, in the UK,

social media companies have lost the trust of most of the public, with only a quarter of the population now saying that they trust social media as a source for news and information. Where social media companies were once seen as champions of free speech and democracy, they are now seen as not taking enough responsibility for key issues, including extremism and fake news.

\subsection{Journalism}

The Edelman survey also reports, perhaps as a consequence of the findings in the above paragraph, "There has been a huge increase in trust in traditional media...and faith in experts and leaders". Certainly, several of the more serious newspapers have issued strong statements of intent concerning their responsibility to combat fake news and the steps being taken to ensure that 
intent. An in-depth study carried out by Cadwalladr (Cadwalladr, 2017) over a period of months described a "system" set up by a billionaire called Robert Mercer, an ex-IBM computer scientist, and the main individual financial donor behind Donald Trump's presidential election campaign. Cadwalladr stumbled across a political advertising network supported by Mercer when she started a Google search with the words "Mainstream media" at which point Google suggested the search "Mainstream media are dead". The first click led Cadwalladr to a site hosted by CNSnews of which she had never heard and which marked the start of her research. She found that CNSnews was owned by the Media Research Center financed by Mercer, involving people such as Steve Bannon, (at that time close to Trump) and which had set up a system through Facebook which had disseminated political propaganda. The trick was to use the personal profiles of users automatically compiled by Facebook inferring their likely attitudes and behaviour, and then magnified by use of the "like button" feature accompanying messages. This produced a dynamic system which successfully targeted individuals and groups with propaganda to breed support for the Trump campaign. This research was followed up with further revelations concerning the involvement of a UK company called Cambridge Analytica which was found to have helped both the U.K. Brexit Leave Campaign and Team Trump in the U.S presidential election. This company is alleged to have "hijacked the profiles of millions of Facebook users as part of a sophisticated cyber-campaign to unleash 'psychological warfare' on the American electorate" (Cadwalladr, 2018). It is worth noting here that the Guardian and Observer newspapers originally belonged to the Scott Trust which maintained their political independence, and which has since been transferred to an equally independent agency. Both the newspapers are also members of the International Consortium of Investigative Journalists (I.C.I.J, n.d.), founded in 1997 as a project of the U.S. Center for Public Integrity and spun off in 2017 as a fully independent news organization including 200 investigative journalists working with 100 media organizations in many countries, including the two papers mentioned above, the New York Times, the Washington Post, the British Broadcasting Corporation, the Spanish La Sexta and El Confidencial, and the French Le Monde.

\subsection{Information Literacy}

Wikipedia cites the definition of Information Literacy as promoted by the U.S. Forum on Information Literacy: "The ability to know when there is a need for information, to be able to identify, locate, evaluate, and effectively use that information for the issue or problem at hand". CILIP goes a useful step further with "Knowing when and why you need information, where to find it, and how to evaluate, use and communicate it in an ethical manner" (CILIP, 2018). CILIP also organizes an annual conference under the title LILAC, standing for Librarian's Annual Information Literacy Conference (LILAC, n.d.). The American Library Association has issued an updated Framework for Information Literacy for Higher Education (ALCR, n.d), (though it has value for the wider community); it is stated "This Framework acknowledges that in updating a previous version it is recognized that the rapidly changing higher education environment, along with the dynamic and often uncertain information ecosystem in which all of us work and live, require new attention to be focused on fundamental values about the ecosystem" (Author's italics). The Framework consists of six headings: Authority is Constructed and Contextual, Information Creation as a Process, Information Value, Research as Inquiry, Scholarship as Conversation, Searching as Strategic Exploration. In the discussion of the Framework there is a useful word defined: Metacognition - "An awareness and understanding of one's own thought processes", pertinent in the wider context to the exposure to fake news.

\subsection{Government and the 'tech giants'}

The beginning of 2018 has seen a notable increase of government action in a number of countries concerned about the dominating influence of the 'tech giants', notably Google, Facebook and Amazon, and this concern is likely to grow. The concerns include their huge profits largely made through monopolistic structures, avoidance of tax and, of most interest to this paper, the spreading of fake news and disinformation, largely through the harvesting of personal profiles allowing the targeting of individuals and groups with propaganda. Moore (Moore, 2017), in a short article under the title "Society will be defined by how we deal with tech giants" reports that the European Union began anti-trust action against Google in 2015; and the German Government is drafting legislation threatening fines of up to $€ 50$ million if social media platforms do not remove offensive content. In early 2018, Mark Zuckerburg was asked to appear before Committees of enquiry in both the U.S. Congress and the U.K. Parliament. The U.K. government has announced the establishment of a Fake News Unit, with the words "The dedicated national security communications unit would be charged with combating disinformation by state actors and others". The recent 
disclosures reported by Cadwalladr and outlined above have helped to stir action in many places and 2018 and beyond are likely to be busy ones for governments and the tech giants.

\subsection{Fact Checking}

The principles of fact checking have been reviewed above, and it has been noted that the end reader cannot be expected to take full responsibility - though, clearly, it is in the personal interests of all to make the effort. It follows that a great responsibility does fall on all those engaged in intermediary tasks in the various information channels, principally journalists and academics, and all those engaged in the information professions. It is the job of journalists to report on the news, the daily or weekly events occurring in their stated areas of concern. Some of these areas are worldwide, some national or local, some focused on specific subjects such as politics, economics, science or the arts and humanities. The reporting should be based, as far as possible, on the facts as they may be understood, though interpretation is not only allowable but desirable in a democratic society, providing such interpretation is openly linked to the stated policy of the publication and the stance of the author, be these for example, right or left wing political, religious or any other of the major belief systems and ideologies. Similarly, teachers in academia should make clear in their lectures and teaching what is 'received wisdom' and what is opinion, particularly where there are conflicting schools of thought. Thus, 'messages' as used in the definitions paragraph at the beginning of this paper should be informative but balanced, inviting and allowing the recipient to make his or her own judgement. The roles of information professionals are somewhat different in that they, to a great extent, deal with the formal outputs of journalists, academics and others and are usually professionally neutral in their opinions of the messages, other than in giving vital and informed comment on sources and other relevant facts about the 'messages'. It follows that any external aids to fact checking are not only extremely useful for journalists, academics and information professionals, but increasingly important in this post-truth world. Goasdoue et al (Goasdoue, Manolescu and Tannier, 2017) present some excellent guidelines for journalists on fact-checking which they place in the wider context of content management. As background, the authors quote a journalist of around the year 1930 saying "The day I became a fact-checker at the New Yorker I received one set of red pencils for underlining passages of page proofs of articles that might contain checkable facts". This was done mainly to protect the publication's reputation. By the beginning of this century the problem was recognized as being more serious when one of the first fact-checking sites was set up by the Annenberg Public Policy Center of the University of Pennsylvania under the URL FactCheck.org. This is a non-partisan and independent operation aimed specifically at the coverage of American politics. The organization provided a useful check-list in 2016 under the title 'How to spot fake news' (Kiely and Robertson, 2016) that has eight headings: Consider the source, Read beyond the headlines, Check the author; What's the support?; Check the date; Is this some kind of joke?; Check your biases; Consult the experts. Academics have followed with similar, but differently focussed check-lists. For example, Walsh (Walsh, 2017) asks "If we don't teach students how to confirm the validity of information they find on the Internet, who will?", and quotes from an eBook (Caulfield, 2017) the advice for students under the headings: Look for previous work; Go upstream (i.e. seek the original source); Read laterally. Goasdoue and her co-authors provide flow diagrams showing the process by which claims for items to be checked are combined with those items input by the authors, subjected to a 'verification tool' and the extracts graded as True, Rather true, Rather false, or False. Further analyses are conducted, using technology where appropriate and available. Sensibly, the authors then point out that "It's not just checking", and that as "most aspects of modern reality are complex, so explaining may be as important and useful as checking". Here they introduce the useful French word 'Décodeurs' perhaps as a riposte to the Coders of Silicon Valley.

\subsection{Fact Checking websites}

Graves and Cherubini, writing from the Reuters Institute at Oxford University (Graves and Cherubini, 2016) have written of the rapid growth of factchecking websites in Europe. The authors report that over the past decade (from the writing of the report in 2016) independent checkers have appeared in over 50 countries across the world and according to reliable research there are 113 active groups, of which more than $90 \%$ were established since 2010 , about 50 in the past year alone (i.e. 2015). Some $63 \%$ of the operations are affiliated to a media organization in the U.S. compared with $44 \%$ outside. The report has collected information from other reputable organizations, including the Poynter Institute and the Duke Reporter's Lab. There are also useful case studies of the French newspaper Le Monde, and their 'Les Décodeurs', and the Italian independent operation Pagella Politica. In their conclusion the authors express some scepticism about the effectiveness of fact- 
checking sites, following the election of President Trump, but are optimistic that fact-checking can help to "both dispel misinformation and inhibit political lying". As noted earlier in this paper such optimism may be well-founded in view of the rise of public trust in journalists and experts.

The oldest fact checking sites are in the U.S., principally FactCheck (FactCheck, 2018), mentioned above and established in 2003 by the Annenberg Institute, part of the University of Pennsylvania. The website states that it is a "nonpartisan, non-profit 'consumer advocate' for voters that aims to reduce the level of deception and confusion in U.S. politics". Other American factchecking websites, addressing issues outside politics include Snopes (Snopes, 2018) which covers 'urban myths' and Hoax-Slayer (Hoax-Slayer, 2018) which focuses on "debunking email and internet hoaxes and combating spam". In Spain, the newspaper El Confidencial (El Confidencial, 2018) operates a fact-checking site called La Chistera (meaning Top Hat). Africa's first fact-checking website Africa Check (AfricaCheck,2018) established in 2012, maintains offices in Johannesburg, Nairobi, Lagos, Dakar and London and broadcasts in English and French.

\subsection{Automated fact-checking}

There is increasing interest in the possibility of automated fact-checking, an interest which is likely to grow as some of the newer 'big data' technologies become available. PHEME (PHEME, 2018 ) is an agency which is building and promoting automated fact-checking by researching the available technologies and, in their words: "We aim to release many of the veracity intelligence algorithms through the many links established". The word PHEME echoes the word meme and is based on Pheme, the Greek goddess of fame and rumours. Following a Gartner report that suggested that social media poses three major computational challenges, dubbed the three Vs, and listed as Volume, Velocity, Variety - PHEME added Veracity. PHEME has nine academic and research-based partners in Austria, Bulgaria, France, Germany, Kenya, Spain, Switzerland and the U.K., and organizes, roughly every year, an event called SemEval which invites fact-checking organizations to run tasks on PHEME problems such as stance detection and veracity assessment. The U.K. independent Full Fact has produced a very useful report (Babakar and Moy, 2016) under the title "The state of automated fact checking" followed by the sub-title "How to make fact checking dramatically more effective with technology we have now". The authors claim that "we are months - and relatively small amounts of money - away from putting practical automated tools in factcheckers and journalists' hands. This is not the horizon of artificial intelligence; it is simply the application of existing technology to factchecking". The authors go on to propose the establishment of open standards and international collaboration so that the systems work in several languages and countries. The 'road map' that they suggest consists of four parts: Monitor, Spot claims, Check claims, Create and publish. With reference to these three requirements, the authors claim they are currently ready to Monitor Twitter, emails and websites; Claim recognition for known claims; Check subject specific claims; Create simple human readable content. The authors are aiming, under the same headings, to be able to Monitor radio or TV with speech recognition; Handle paraphrases; Check any claim better than a human with the Internet; Create persuasive human-friendly content and tools. Full Fact was granted a start-up sum of $€ 50.000$ by Google and have since received a further $€ 500,000$ from the Omidyar Foundation and the Open Society Foundation. It is possible to subscribe to a mailing list on this website for updates on progress. Google is also financing a research initiative in the Department of Journalism at London's City University amounting to $£ 300,000$ under the title DMINR (standing for Data Mining In News Rooms) (Grover, 2017). The research will be tested in some 30 news rooms across Europe, covering a large amount of data and several languages. So, there is much activity in many countries and much of it seems to be sensibly co-ordinated, but a word of caution is issued by Graves of the Reuters Institute (Graves, 2018). The author points out that fact-checking initiatives and research normally have three inter-related objectives: spotting false or questionable online claims; authoritatively verifying such claims; and delivering instantaneous corrections and, while admitting that important advances have been made and are continuously being made in many places and institutions, "the potential for automated responses to online misinformation that work at scale and don't require human supervision remain sharply limited today".

\section{Updates and Conclusions}

The first draft of this paper was written in March/April 2018, shortly after the explosion of interest in the post-truth phenomenon. As there have been few dramatic developments since then, this final section adds some updates and brief conclusions. One major study is worth reporting, that conducted by the Massachusetts Institute of Technology into the nature and spread of fake news (Robinson, 2018). This study analysed every major contested news story in English 
across the span of Twitter's existence - some 126,000 stories, tweeted by 3 million users over more than ten years. The study found that "fake news and false rumours reach more people, penetrate deeper into the social network and spread much faster than accurate stories". Furthermore "A false story reaches 1,500 people six times quicker, on average, than a true story". The report concludes with the question "Why does falsehood do so well" and suggests that it is because "1. Fake news seems to be more "novel" than real news and 2. Fake news evokes much more emotion than the average tweet." The study poses the enormous question: "How can we create a news ecosystem - that values and promotes truth?".

Cadwalladr has continued her marathon investigations into the networks misusing the social media platforms to spread disinformation (Cadwalladr, 2018) and has been awarded the Orwell prize for outstanding journalism (named after George Orwell, author of 1984, the prize perpetuated by his descendants). The latest facts uncovered by Cadwalladr are that at least one of the pro-Brexit campaign organizations breached the regulations monitored by the Electoral Commission, the official 'watchdog' appointed by the Government. The investigations by Cadwalladr have continued for many months and have been reported in The Guardian and its sister paper The Observer in a series of articles and shorter updates resulting in, among other results, the demise of the data processing firm Cambridge Analytica and a formal investigation being carried out by the Electoral Commission. However, as the saying goes "The wheels of government grind exceeding small" and it may be some time before meaningful results occur. Following the fact that it has been shown that Facebook shared data on 57 billion friendships, the company is now beginning to take action. Earlier in this paper it was reported that Zuckerberg had been "invited" to appear before Committees in the American government Congress and the U.K Parliament. In fact, Zuckerberg declined the invitation from the U.K. but appeared before the American Committee and also one convened by the Parliament of the E.U. Reports of the meetings suggested that they were rather bland, but Facebook has since taken certain steps, including the deletion of much data, introducing new improvements to the system and hiring a large number of fact checkers. Government, in general, is moving more slowly, looking more closely at the enormous power of the tech giants and considering what actions to take and whether these should be taken at the national or international levels. Meanwhile it has set up a House of Commons Select Committee to investigate the topic of fake news.
The UK Chapter of the International Society for Knowledge Organization devoted part of its $\mathrm{Bi}$ Annual Conference to the subject of this paper, under the title "False narratives: developing a $\mathrm{KO}$ community response to post-truth issues", with papers by a journalist, the Chief Executive of $\mathrm{Cl}$ LIP and David Clarke (co-founder and CEO of the Synaptica Group of companies, providers of enterprise software solutions for knowledge organization and discovery ). The papers are available on ISKO UK's website ((ISKO UK, 2017). Two of the speakers at the Conference took part in a later ISKO UK afternoon meeting - Nick Poole, the Chief Executive of CILIP and David Clarke (ISKO UK, 2018). Both these meetings were notable for including papers by journalists and different branches of the information professional communities. This collaboration between different strands of information intermediaries is to be applauded, as is Dave Clarke's personal efforts to raise the issue of post truth in a collaborative environment. His efforts can be found on his blog (Clarke n.d.) with particular attention to be paid to the Post Truth Forum. (Post Truth Forum, n.d.)

Government, the big tech giants, journalists, academia and the different branches of the information professions must all work together in the fight against post-truth, backed by a clear understanding of the roots of the problem and the dissatisfactions and comparative alienation of many of the ordinary people, and one should hope that the way forward is led by government, aided by the professions. As Carole Cadwalladr said in her speech at the Orwell award ceremony: "What we are seeing here is a systemic failure. Our laws do not work and our regulations are unable to regulate. We do not have the information we need from the high-tech platforms."

Finally, a brief quote from Robert Fairthorne, one of the eminent British information scientists of the 1960/1970s: "Information scientists do not give information, they give information about information". This is even more vitally relevant in 2018 .

\section{References}

ACRL (2016) Framework for Information Literacy for Higher Education. www.ala.org/acrl/standards/ilframework

AfricaCheck. https://africacheck.org

Babakar, Mevan; Moy, Will. The state of automated fact checking. // Full fact. https://fullfact.org/automated

Baggini, Julian (2017). A Short History of Truth. London: Quercus.

Ball, James (2017). Post-Truth. London: Biteback Publishing Limited. 2017.

Bawden, David; Robinson, Lyn (2016). Information and the gaining of understanding. // Journal of Information Science. 42:3, 294-299. 
Belkin, Nicholas J.; Robertson, Stephen (1976). Information science and the phenomenon of information. // Journal of the American Society of Information Science. 27, 197-204.

Botsman, Rachel (2017). Who can you trust? London: Penguin Random House. 2017.

Cadwalladr, Carole (2016). Google, democracy and the truth about internet search. // The Guardian. 2016-12-04. theguardian.com/technology/2016/dec/04/google-democracy-truth-internet-search-facebook.

Cadwalladr, Carole (2017). Robert Mercer: the big data billionaire waging war on mainstream media. // The Guardian. 2017-02-26. https://theguardian.com/politics/2017/ feb/26/robert-mercer-breitbart-war-on-media-steve-bannon-donald-trump-nigel-farage

Cadwalladr, Carole (2018). The Cambridge Analytica Files. // The Guardian, 21 March, 2018, 6-7.

Cadwalladr, Carole (2018). It's a fight for the soul of our electoral system. // The Observer. 8 July 2018, 31-32.

Caulfield, Michael (2017). Web literacy for student fact-checkers. https://webliteracy.pressbooks.com

Cherubini, Federica; Graves, Lucas (2016). The rise of factchecking sites in Europe. Oxford: Reuters Institute. https://reutersinstitute.politics.ox.ac.uk/our-research/risefact-checking-sites-europe (with link to main report).

CILIP. https://www.cilip.org.uk/page/trusted

CILIP, Information Literacy Group. Information literacyhttps://infolit.org.uk

Clarke, Dave. www.davidclarke.blog

Collins, Mike (2015). The Pros And Cons Of Globalization . // Forbes. 2015-05-06. www.forbes.com/sites/mikecollins/ 2015/05/06/the-pros-and-cons-of-globalization/\#43190fb 8 ccce.

Coughlan, Sean (2017). What does post-truth mean for a philosopher? [A.C. Grayling]. BBC News. 2017-01-12. http://bbc.co.uk/news/education-38557838

D'Ancona, Matthew (2017). Post Truth: The New War on Truth and How to Fight Back. London: Ebury Publishing.

Edelman Trust. https://www.edelman.co.uk/magazine/posts/ edelman-trust-barometer-2018

El Confidencial. www.elconfidencial.com

FactCheck. www.factcheck.org

Floridi, Luciano (2010). Information: A Very Short Introduction. Oxford: Oxford University Press.

Fowler, Daniel S. (2014-2018). How Many Websites Are There In The World?. Tek Eye. tekeye.uk/computing/howmany-websites-are-there

Geiger, Abigail (2017). Most Americans - especially Millennials - say libraries can help them find reliable, trustworthy information. // Pew Research. 2017-08-30. www.pewresearch.org/fact-tank/2017/08/30/most-americans-especially-millennials-say-libraries-can-help-them-find-reliable-trustworthy-information

Goasdoue Francois; Manolescu, Ioana; Tannier, Xavier (2017). Content management techniques and tools for fact-checking. www.paris-bigdata.org./2017/slides/manolescu.pdf.

Graves, Lucas (2018). Understanding the promise and limits of automated fact-checking. // Factsheet. 2018-02. http://reutersinstitute.politics.ox.ac.uk/sites/default/files/ 2018-02/graves_factsheet_180226\%20FINAL.pdf

Grover, Ed. (2017). City journalism academics to lead European big data and fake news project. London: City, University of London. https://www.city.ac.uk/news/2017/ june/google-digital-news-initiative-dminr

Hoax-Slayer. www.hoax-slayer.net.
Horrigan, John B. (2017). How people approach facts and information. // Pew Research Center.2017-09-11. www.pewinternet.org./2017/09/11/how-people-approachfacts-and-information

Huwe, Terence K. (2017). Fake news and the librarian's duty of care. // Info Today. 2017-03-31. https://www.infotoday.eu/Articles/Editorial/Featured-Articles/Fake-newsand-the-librarians-duty-of-care-117248.aspx

ICIJ. https://www.icij.org

IFLA. How to spot fake news - IFLA in the post-truth society. https://www.ifla.org/node/11175

Ingwersen, Peter (1996). Cognitive perspectives of information retrieval interaction; elements of a cognitive IR theory. // Journal of Documentation. 52, 3-50.

ISKO UK. Knowledge Organization - what's the story? Classification, Indexing, Taxonomies and Ontologies - current state and direction of travel: ISKO UK biennial conference, 11th - 12th September 2017, London. www.iskouk.org/content/isko-uk-conference-2017-knowledgeorganization-whats-story

ISKO UK. Knowledge Organization and Ethics, 19 March 2018. www.iskouk.org/content/knowledge-organizationand-ethics

Kiely, Eugene; Robertson, Lori (2016). How to spot fake news. // FactCheck.org. 2016-11-18. https://www.fact check.org/2016/11/how-to-spot-fake-news

LILAC. https://www.lilacconference.com

Lister, Mary (2017-2018). 40 Essential Social Media Marketing Statistics for 2018.Last updated:July 25, 2018. https://www.wordstream.com/blog/ws/2017/01/05/socialmedia-marketing-statistics.

Moore, Martin (2017). Society will be defined by how we deal with the tech giants. // The Guardian. 2 Apr 2017. https://www.theguardian.com/commentisfree/2017/apr/ 01/brexit-britain-respond-tech-giants-civic-role-googleapple-facebook-amazon-eu

M.S. What is populism? // The Economist explains. Dec 19th 2016. https://www.economist.com/blogs/economist-explains/2016/12/economist-explains-18

Nielsen, Rasmus Kleis; Graves, Lucas (2017). "News you don't believe": Audience perspectives on fake news. Oxford: Reuters Institute. https://reutersinstitute.politics.ox. ac.uk/our-research/news-you-dont-believe-audience-perspectives-fake-news

Nonaka, Ikijuru; Takeuchi, Hirotaka (1995). The Knowledge Creating Company. Oxford: Oxford University Press.

PHEME. www.pheme.eu.

Post Truth Forum. www.posttruthforum.org

Robinson, Meyer (2018). The Grim Conclusions of the Largest-Ever Study of Fake News. // The Atlantic. March 8, 2018. https://www.theatlantic.com/technology/archive/20 18/03/largest-study-ever-fake-news-mit-twitter/555104/

Snopes. www.snopes.com

Snyder, Timothy (2017). On Tyranny: Twenty Lessons from the Twentieth Century. London: The Bodley Head.

Steinberg, Luc (2017). Beyond fake news. // Eavi. July 26th, 2017. https://eavi.eu/beyond-fake-news-10-types-misleading-info/

Verstraete, Mark; Bambauer, Derek E.; Bambauer, Jane E. (2017). Identifying and countering fake news. // Arizona Legal Studies Discussion Paper No. 17-15. https://law.arizona.edu/report-identifying-and-countering-fake-news

Walsh, Kelly (2017). Sharing a great resource and techniques for web content fact-checking. // Emerging EdTech. July 12, 2017. www.emergingedtech.com/2017/07/resourcetechniques-for-web-fact-checking 
Wardle, Claire. Fake news: It's complicated. // First Draf. February $16,2017$. https://firstdraftnews.com/fake-newscomplicated.
Enviado: 2017-04-10. Segunda versión: 2018-07-13 Aceptado: 2018-09-06. 